\title{
Impact of Weather and Herd Size Management on Beef Cow Profitability
}

\author{
Colson A. Tester ${ }^{1}$, Michael P. Popp ${ }^{1, \star(D)}$, Nathan P. Kemper ${ }^{1}$, Lanier L. Nalley ${ }^{1}$ and Grant West ${ }^{1}$ \\ ${ }^{1}$ Department of Agricultural Economics and Agribusiness, University of Arkansas, Fayetteville, Arkansas, USA \\ ${ }^{\star}$ Corresponding author. Email: mpopp@uark.edu
}

\begin{abstract}
Producers often contemplate expanding or contracting production to take advantage of cyclical cattle price trends. This study quantifies profitability and risk implications of (1) constant herd size, (2) dollar cost averaging, and (3) price signal-based, anticipatory countercyclical expansion/contraction strategies. Weather simulation on forages with different calving season and land use intensity showed fall calving herds with added hay sales from greater fertilizer use and the countercyclical herd size management strategy to be most profitable regardless of weather or time period analyzed. Income risk was comparable to least fertilizer use. Overall, holding herd size constant led to little regret.
\end{abstract}

Keywords: Calving season; cow-calf production; fertilizer use; herd size management; price cycles; weather uncertainty

\section{Introduction}

Cattle production is an important industry to agriculture in many U.S. states as cattle and calf sales amounted to $21 \%$ of aggregate U.S. agricultural commodity sales of $\$ 78.2$ billion in 2015 (U.S. Department of Agriculture, National Agricultural Statistics Services [USDA-NASS], 2016). Changes in the U.S. herd size, attributed to weather (specifically drought), macroeconomic factors, and varying cattle and feed prices, can have large economic repercussions for the livestock sector. For example, with the expanded use of corn for ethanol production over the course of the last 20 years, U.S. corn prices eventually increased enough to make it the most valuable commodity in terms of total production value rather than cattle and calves in 2005 (Park and Fortenberry, 2007). The national drought in 2011-2012 led to large-scale herd liquidation resulting in subsequent, record cattle prices for 2012-2015. These record cattle prices, in turn, caused the eventual rebuilding of the U.S. herd to end the 2004-2014 cattle cycle.

The average cattle cycle, defined as the time span between sequential inventory lows, typically lasts from 8 to 12 years (Mathews et al., 1999) as a function of (1) beef export/import conditions with fluctuating exchange rates, disease outbreaks, and/or trade restrictions; (2) cattle and feed prices; (3) weather events; (4) producer credit constraints (Bierlen et al. 1998); and (5) a biological production lag where an added heifer retained at 7 months of age and bred at 15 months of age leads to an extra calf born and finished as early as 36 months after the retained heifer was born. Hence, national herd expansion is slow compared with possible contraction via the slaughter of mature cows. Furthermore, Hamilton and Kastens (2000) show that, in addition to the abovementioned exogenous factors, market timing attempts by producers are a significant determinant of cattle price cycles. Also, cow-calf production occurs mainly on pastures and encompasses a majority of the time needed from birth to slaughter. Pasturing cattle is characterized by production uncertainty because of drought, flooding, fires, and snow events that affect forage availability and 
thereby cost of production to a larger extent than confined animal feeding conditions for competing meat products of pork and poultry (Mathews et al., 1999). Rosen (1987) proposes that producers capitalize on these factors by selling (retaining) calves when the exogenous shock results in an increase (decrease) in the market price. This type of behavior, however, perpetuates the price cycle.

Careful planning and flexibility to respond to these price cycles by way of herd size expansion/reduction and/or on-farm forage production and acquisition of supplemental feed is required to maintain adequate cash flow, to manage income tax repercussions, and to manage price and production risks (Hughes, 2000). Further, the larger a producer's herd, the larger the potential financial implications. The average U.S. cow-calf operation has approximately 40 head (USDA-NASS, 2019), and operations of this size or smaller are often nonintensive labor enterprises on small parcels of grassland providing a source of supplemental income. Operations of less than 100 head encompass $91 \%$ of operations but represent less than half of the total cattle inventory (USDA-NASS, 2019). On the other hand, operations with more than 100 head account for $51 \%$ of U.S. cattle inventories, while only $9 \%$ of total operations (USDA-NASS, 2019). It is this latter size category where herd size management (HSM) begins to play a more noticeable role on profitability in dollar terms rather than rates of return to resources employed when compared with smaller operations.

Generally, producers expand herd size when prices and producers' returns are high resulting in an increased beef supply several years later (Bentley and Shumway, 1981). However, with expansion of beef supply comes the inevitable decline in prices, and hence, the decision to expand the herd in years past was potentially counterproductive. Expanding the herd when prices are high and liquidating when prices turn low is contrary to the old adage of "buy low, sell high," and thus it may be beneficial for producers to countercyclically expand production when prices are low and decrease herd size when prices are high (Griffith, Burdine, and Anderson, 2017). Along the same line, Hamilton and Kastens (2000) show that a countercyclical strategy outperforms constant herd size (CHS) and cyclical strategies over a 25-year period. Thus, an HSM strategy that anticipates future price trends is encouraged (Bentley and Shumway, 1981; Lawrence, 2002; Trapp, 1986) as HSM strategies that react to price signals can lead to greater returns when compared with strategies that hold the herd size constant. In that regard, Lawrence (2002), compared a CHS strategy to (1) a strategy where sales receipts from heifer sales are constant and thereby more/fewer heifers are sold during low/high price years, respectively, and (2) a dollar cost averaging (DCA) strategy where replacement heifer reinvestment is held constant by again changing the number of heifers retained with changing cattle prices (selling more/fewer when prices are high/low). Lawrence (2002) encouraged the DCA strategy. However, weather effects were excluded and extra land resources were rented when needed and assumed to be available. A study by Lutes and Popp (2015) showed the impacts of weather to increase 10-year income risk under both constant and changing herd size scenarios when land resources are held constant. Herd size changes followed state cattle inventory changes reflecting average producer choices. They used a cow/calf simulation tool, the Forage and Cattle Planner (FORCAP) and analyzed the effect of alternative grazing methods and associated stocking rates (Popp et al., 2014).

Using FORCAP, the objective of this research was to examine cow/calf cash operating profitability with a fixed land resource and three HSM strategies both with and without weather effects over the course of the last two cattle cycles. Because cow-calf operations can modify calving season and amount of fertilizer use, we compare CHS and DCA HSM strategies along with a strategy based on moving average (MA) prices. The MA strategy involves the use of a price ratio of a shortto a longer-run MA to signal an up- or downtrend in cattle prices. The MA strategy thus allows an anticipatory countercyclical herd expansion/contraction reaction to profit from price changes. Results quantify to what extent profit-maximizing, long-term calving season, fertilizer use, and HSM strategy choices are affected by (1) simulated weather effects on forage production generated using satellite imagery and (2) time period or cattle cycle analyzed. 


\section{Materials and methods}

\subsection{Forage and Cattle Planner}

FORCAP (available at http://agribusiness.uark.edu/decision-support-software.php\#forcap) is a decision tool that allows comparison of a plethora of different cattle production practices. The user specifies either default or operation-specific production parameters in an automated spreadsheet application that summarizes profitability and production efficiency changes. ${ }^{1}$ Smith et al. (2016) used the tool in an optimization framework, but this was not possible for this work as the multiyear framework to analyze cattle cycles required hundreds of annual FORCAP model runs. Farm size, as measured by stocking rate and land use (dedicated to pasture or hay production), is a key parameter as are calving season, use of fertilizer inputs, and forage production as affected by weather. Cash operating profits $(\pi)$ are estimated annually and result from sale of cattle and excess hay after accounting for feed and supplements, seed, fuel, fertilizer, twine, chemicals, medication, vaccines, veterinary services, operating interest, repairs, and maintenance as shown for a sample year in Table 1. Different calving seasons lead to changes in exposure to fescue toxicity and thereby a lower breeding failure rate with fall calving than spring calving (Caldwell et al., 2013). Hence, fewer head of calves were sold with spring calving at seasonally lower annual calf and cull cattle prices as reflected in the lower gross receipts and lower direct costs associated with lesser sales when compared with fall calving. Forage production uncertainty, as highlighted in Figure 1 and evident in feeding statistics in Tables 2 and 3, led to monthly changes in forage production that in turn affected hay production and supplemental feed needs given herd nutrition requirements that are affected by cow gestation and lactation needs estimated from month to month. Noticeable for 2004 was the need for purchased hay given less than expected forage production throughout the year except July (Figure 1). This translated to a need for purchased hay as most major forage production months were affected negatively and more so under spring than fall calving conditions in that year. By the same token, supplemental feeding of corn during the winter months was higher with fall than spring calving as nutritional needs of the cows peak in the winter months when lactating to support calves that were born in fall.

Capital ownership charges including depreciation, insurance, property taxes, and opportunity cost of capital were excluded as land, equipment, and building resources used did not change across production practices discussed next. The exception was a set of model runs involving a higher stocking rate that did require added capital investment in breeding stock. Ramifications of these added capital recovery charges and property taxes are discussed subsequently.

\subsection{Land use intensity}

For each of the three HSM strategies (CHS, DCA, and MA), three levels of fertilizer application rates were analyzed to showcase the impact of varying cattle and hay output on profitability while holding pasture and hay land constant over time (Table 4). Further, these nine herd size strategy $\times$ land use intensity (LUI) combinations were analyzed (1) by calving season (fall vs. spring), (2) with and without weather effects on forage and attendant hay production, and (3) over two cattle cycles.

\footnotetext{
${ }^{1}$ Production parameters that can be changed in FORCAP include the following: grazing method (continuous vs. rotational), use of stockpiling and/or winter annuals, selection of forage species on pasture and hay land, level of fertilizer use, choice of herd genetics, animal weights at different growth stages, type and quantity of supplemental feed use, heifer breeding age, breeding failure rates and death losses, calving season, weaning age, year of input and output price, vaccination program, veterinary, and transport charges. Although the program tracks ownership charges for equipment, buildings, fence, and watering facilities, these costs are excluded in this analysis as they do not vary significantly when a change in land resources was not considered. Note that changes in breeding stock between 100 and 160 cows were modeled, but effects of minor cow herd changes across time that exist with MA and DCA strategies in comparison with the CHS strategy were excluded. The value of breeding stock was constant over time at long-term average prices as effects of timing of industry entry and exit were also not examined.
} 
Table 1. Sample of estimated gross receipts and direct costs of a 100-cow herd by calving season and weather effects in 2004 using least fertilizer

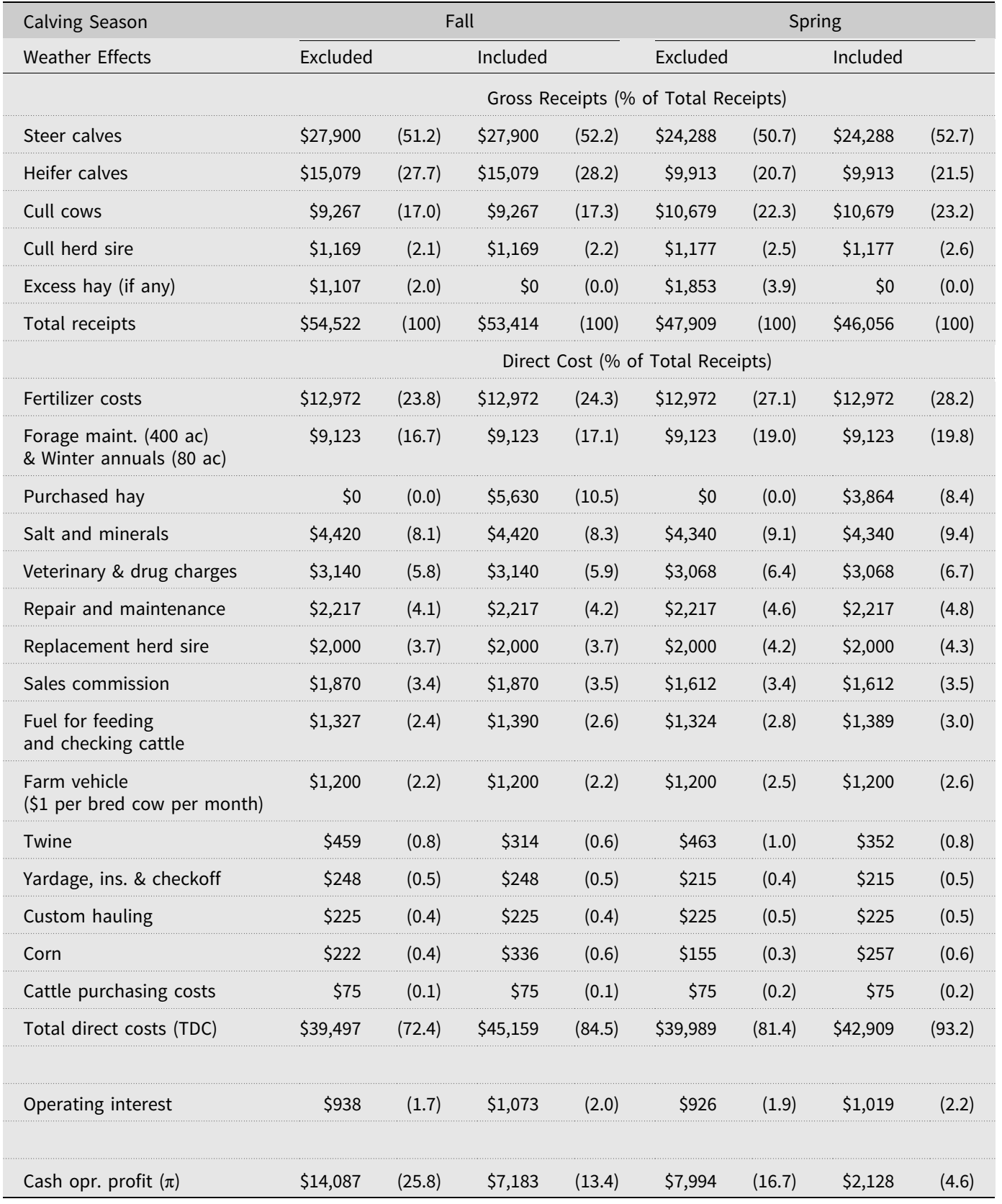

As summarized in Table 4, LUI was increased from left to right by increasing fertilizer application. Least fertilizer use yielded a small hay surplus that was indicative of an operation that relied mainly on cattle revenue for income in the left column. Adding fertilizer on pasture allowed greater opportunity to harvest excess hay from pasture and diversified revenue streams given added hay sales in the middle column. Adding even more fertilizer increased forage production sufficiently to allow a higher cattle stocking rate with hay sales similar to the least fertilizer 

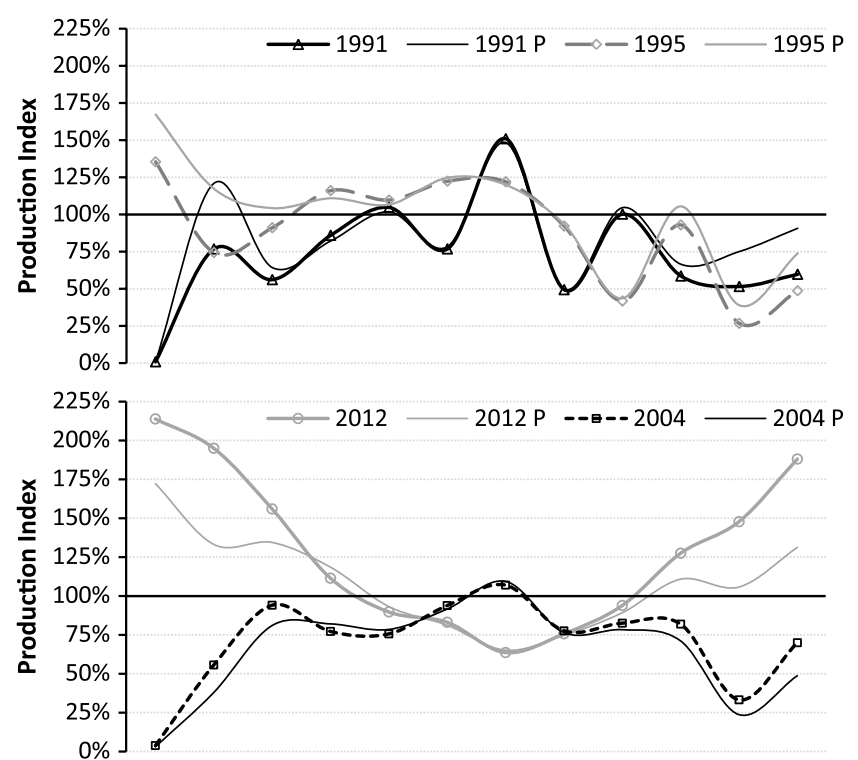

Figure 1. Forage production index values by month and year for select years using 25-year and period-specific $(P)$ averages in the denominator for the production index. Notes: Percentage values represent standardized production index values as specified in equations (1) and (2) for select years shown. A production index value of $100 \%$ represents an expected production year. Using periodspecific production indexes (top two panels), as opposed to the long-run production index (bottom panel), affected forage production adjustments mainly for winter months. Noticeably, and not isolated to the select years shown, forage production was slightly higher using the period-specific index compared with the long-run index in the first cycle, and the obverse was true for the second cycle.

outcome (right column). Forage productivity with different fertilizer application rates was uncertain, however, as weather affects production and thereby the need for and cost of hay and corn feeding. Although the impact of weather uncertainty on supplemental feed and hay sales was highlighted in Tables 1-3 for least fertilizer use, greater fertilizer use amplified weather effects on forage production as discussed next.

\subsection{Production index}

Monthly forage production was tracked historically using imagery and associated NDVI (Normalized Difference Vegetation Index) data collected by LANDSAT. LANDSAT typically reports two NDVI values per month for a specific location (30-m spatial resolution). Chosen for this analysis were six pasture/hay land areas in Washington County in northwest Arkansas as the researchers were familiar with the history of those fields from casual observation over time. The fields were also identified using historical cropland data layer data available through USDA-NASS (2017) as far back as 2008, to have at least partial assurance that the fields were in pasture or hay land production throughout the analyzed period, 1990-2014. Therefore, 12 NDVI values per month (two each for six locations), except for some missing observations with data collection problems like cloud cover, for example, were available to create a time-varying vegetation index that would lend itself to capture weather impacts on forage 


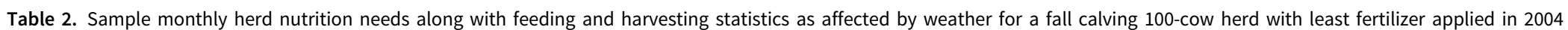

\begin{tabular}{|c|c|c|c|c|c|c|c|c|c|c|c|c|c|c|c|c|}
\hline \multirow[b]{3}{*}{ Month } & \multicolumn{6}{|c|}{ Forage Requirement in cwt. ${ }^{a}$ to Meet Nutrition Needs by Cattle Type } & \multicolumn{6}{|c|}{ Feeding Statistics in cwt. to Meet Herd Needs } & \multicolumn{2}{|c|}{$\begin{array}{l}\text { Est. Days } \\
\text { with Feed } \\
\text { Supplement }\end{array}$} & \multicolumn{2}{|c|}{$\begin{array}{c}\text { Excess } \\
\text { Hay Bales } \\
\text { Harvested } \\
\text { from } \\
\text { Pasture }^{f}\end{array}$} \\
\hline & \multirow[b]{2}{*}{ Cows $^{b}$} & \multirow[b]{2}{*}{ Bulls } & \multirow[b]{2}{*}{ Repl.c } & \multirow[b]{2}{*}{ Heifer Calves ${ }^{d}$} & \multirow[b]{2}{*}{ Steer Calves ${ }^{\mathrm{d}}$} & \multirow[b]{2}{*}{ Total } & \multicolumn{2}{|c|}{ Grazing } & \multicolumn{2}{|c|}{ Hay Fed } & \multicolumn{2}{|c|}{ Corn Fed } & \multirow[b]{2}{*}{ Excl. } & \multirow[b]{2}{*}{ Incl. } & \multirow[b]{2}{*}{ Excl. } & \multirow[b]{2}{*}{ Incl. } \\
\hline & & & & & & & Excl. ${ }^{e}$ & Incl. & Excl. & Incl. & Excl. & Incl. & & & & \\
\hline Jan & 914 & 43 & & & & 957 & 73 & 3 & 884 & 954 & 27 & 40 & 29 & 31 & & \\
\hline Feb & 788 & 39 & & 24 & 25 & 875 & 356 & 198 & 519 & 677 & 15 & 31 & 17 & 22 & & \\
\hline Mar & 828 & 43 & & 62 & 61 & 994 & 787 & 740 & 207 & 254 & & & 6 & 8 & & \\
\hline Apr & 767 & 41 & & 97 & 103 & 1,008 & 1,008 & 1,008 & & & & & & & & \\
\hline May & 665 & 43 & & 143 & 152 & 1,002 & 1,002 & 1,002 & & & & & & & 45 & \\
\hline Jun & 655 & 41 & 77 & & & 773 & 773 & 773 & & & & & & & 48 & \\
\hline Jul & 689 & 43 & 84 & & & 815 & 815 & 815 & & & & & & & 44 & 39 \\
\hline Aug & 721 & 43 & 89 & & & 853 & 465 & 360 & 388 & 464 & & & 14 & 17 & & \\
\hline Sep & 692 & 41 & 94 & & & 827 & 327 & 270 & 500 & 557 & & & 18 & 20 & & \\
\hline Oct & 730 & 43 & 104 & & & 877 & 683 & 560 & 194 & 318 & & & 7 & 11 & & \\
\hline Nov & 839 & 41 & & & & 880 & 607 & 201 & 273 & 679 & & & 9 & 23 & & \\
\hline Dec & 908 & 43 & & & & 951 & 165 & 115 & 786 & 836 & & & 26 & 27 & & \\
\hline
\end{tabular}

${ }^{2}$ Forage requirements were calculated on the basis of dry matter intake needs of the different animal types and their weights given monthly available forage and hay resources. In months where total digestible

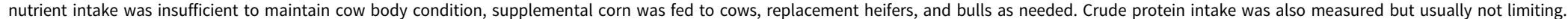
${ }^{b}$ Cows were culled as a function of age or if open. All animals culled were sold in May when calves born in the previous October were weaned. ${ }^{C}$ Replacement heifers are calves fed to replace cull animals and become part of the nutrient needs of the cow herd once 13 months of age.

dHeifer and steer calves begin grazing at 4 months of age thereby reducing cow nutrition needs.

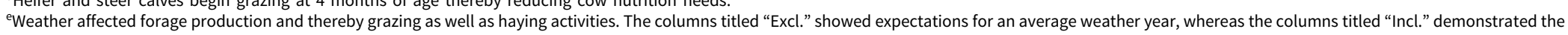
impact of adjusting monthly forage production by the production index as shown in Figure 1. Forage quality changes because of weather were not included.

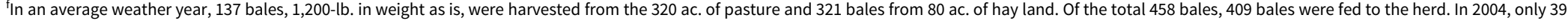
and 274 bales were produced on pasture and hay land, respectively, and 517 bales were fed to the herd when weather effects were included. 


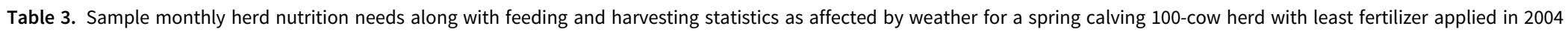

\begin{tabular}{|c|c|c|c|c|c|c|c|c|c|c|c|c|c|c|c|c|}
\hline \multirow[b]{3}{*}{ Month } & \multicolumn{6}{|c|}{ Forage Requirement in cwt. ${ }^{a}$ to Meet Nutrition Needs by Cattle Type } & \multicolumn{6}{|c|}{ Feeding Statistics in cwt. to Meet Herd Needs } & \multicolumn{2}{|c|}{$\begin{array}{c}\text { Est. Days } \\
\text { with Feed } \\
\text { Supplement }\end{array}$} & \multicolumn{2}{|c|}{$\begin{array}{c}\text { Excess Hay } \\
\text { Bales } \\
\text { Harvested } \\
\text { from } \\
\text { Pasture }^{f}\end{array}$} \\
\hline & \multirow[b]{2}{*}{ Cows $^{\mathrm{b}}$} & \multirow[b]{2}{*}{ Bulls } & \multirow[b]{2}{*}{ Repl. $^{c}$} & \multirow[b]{2}{*}{ Heifer Calves ${ }^{d}$} & \multirow[b]{2}{*}{ Steer Calves ${ }^{d}$} & \multirow[b]{2}{*}{ Total } & \multicolumn{2}{|c|}{ Grazing } & \multicolumn{2}{|c|}{ Hay Fed } & \multicolumn{2}{|c|}{ Corn Fed } & \multirow[b]{2}{*}{ Excl. } & \multirow[b]{2}{*}{ Incl. } & \multirow[b]{2}{*}{ Excl. } & \multirow[b]{2}{*}{ Incl. } \\
\hline & & & & & & & Excl. ${ }^{\mathrm{e}}$ & Incl. & Excl. & Incl. & Excl. & Incl. & & & & \\
\hline Jan & 661 & 43 & 98 & & & 802 & 73 & 2 & 729 & 800 & 18 & 29 & 28 & 31 & & \\
\hline Feb & 626 & 39 & 94 & & & 758 & 356 & 135 & 402 & 623 & 8 & 28 & 15 & 23 & & \\
\hline Mar & 687 & 43 & 113 & & & 842 & 787 & 637 & 56 & 205 & & & 2 & 8 & & \\
\hline Apr & 679 & 41 & 118 & & & 838 & 838 & 838 & & & & & & & & \\
\hline May & 832 & 43 & & & & 875 & 875 & 875 & & & & & & & 60 & 36 \\
\hline Jun & 844 & 41 & & & & 885 & 885 & 885 & & & & & & & 59 & 30 \\
\hline Jul & 878 & 43 & & & & 921 & 792 & 867 & & & & & & & 24 & 22 \\
\hline Aug & 838 & 43 & & 23 & 24 & 927 & 465 & 355 & 463 & 572 & & & 15 & 19 & & \\
\hline Sep & 770 & 41 & & 52 & 51 & 914 & 327 & 256 & 587 & 658 & & & 19 & 22 & & \\
\hline Oct & 761 & 43 & & 86 & 92 & 982 & 683 & 486 & 299 & 496 & & & 9 & 16 & & \\
\hline Nov & 618 & 41 & & 120 & 128 & 906 & 607 & 144 & 300 & 762 & & & 10 & 25 & & \\
\hline Dec & 650 & 43 & 93 & & & 786 & 165 & 80 & 621 & 705 & & & 25 & 28 & & \\
\hline
\end{tabular}

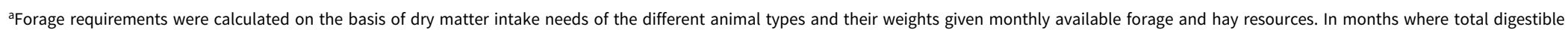

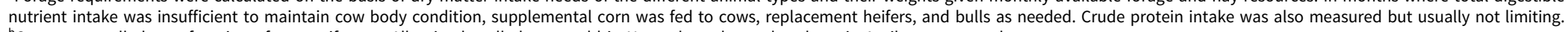
${ }^{\mathrm{b} C}$ Cows were culled as a function of age or if open. All animals culled were sold in November when calves born in April were weaned.

${ }^{c}$ Replacement heifers are calves fed to replace cull animals and become part of the nutrient needs of the cow herd once 13 months of age.

dHeifer and steer calves begin grazing at 4 months of age thereby reducing cow nutrition needs.

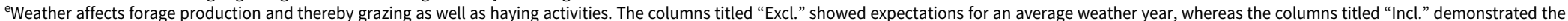
impact of adjusting monthly forage production by the production index as shown in Figure 1. Forage quality changes because of weather were not included.

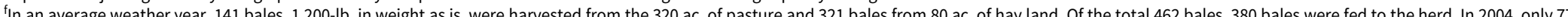
and 274 bales were produced on pasture and hay land, respectively, and 491 bales were fed to the herd when weather effects were included. 
Table 4. Summary of ranch productivity by calving season as affected by fertilizer application using a constant herd size management strategy without weather effects

\begin{tabular}{lccc}
\hline Land Use Intensity & Low & Medium & High \\
\hline Hay land fertilizer: & & & 100 \\
\hline Ammonium nitrate in lb./ac. & 100 & 2 & 300 \\
\hline Poultry litter in tons/ac. & 2 & & 3 \\
\hline Pasture fertilizer: & 0 & 0 & 100 \\
\hline Ammonium nitrate in lb./ac. & 0.5 & 1 & 2 \\
\hline Poultry litter in tons/ac. & 100 & 100 & 160 \\
\hline No. cows bred annually & 49 & 171 & 46 \\
\hline Hay sales, fall & 87 & 221 & 119 \\
\hline Hay sales, spring & a & & 2 \\
\hline
\end{tabular}

${ }^{a}$ Hay sales were the number of surplus $1,200-\mathrm{lb}$. round bales sold. Hay sales or purchases were a function of seasonal forage production and herd nutrition needs. Weather effects were excluded here, but forage production detail is shown in Figure 1 as well as Tables 1-3, 5, and 6.

production. ${ }^{2}$ To capture changes in forage production, the ratio of an individual month's average NDVI value for all six fields for a given year to its 25-year average (1990-2014) for a particular month indicated deviations from long-term conditions observed for each month. Note that these fields likely had different forage species mixes over time, but those trends are not discernable from either the cropland data layer or satellite imagery. Hence, average NDVI values of six fields were used to remove variability in forage species crop mix that might occur on a single field. These ratios were further divided by the average of the examined period ratio values to create a production index that would average to $100 \%$ over the period as follows:

$$
\begin{gathered}
R P I_{i j}=\frac{N D V I_{i j}}{\left(\frac{\left(\sum_{j} N D V I_{i j}\right)}{25}\right)} \forall i=\text { Jan. }- \text { Dec. and } \forall j=1990-2014, \\
P I_{i j_{k}}=\frac{R P I_{i j_{k}}}{\left(\frac{\left(\sum_{j_{k}} R P I_{i j_{k}}\right)}{Y_{k}}\right)}, \forall i=\text { Jan. -Dec., and }\left\{\begin{array}{l}
\forall j_{k}=1990-2003 \text { where } Y_{k}=14 \text {, or } \\
\forall j_{k}=2004-2014 \text { where } Y_{k}=11 \text { or } \\
\forall j_{k}=1990-2014 \text { where } Y_{k}=25,
\end{array}\right.
\end{gathered}
$$

where RPI is the raw production index, NDVI is the six-field average for a particular month $i$ in year $j$, and $P I$ is the standardized production index that varies by production period, $Y_{k}$.

A $P I$ value above/below 1 indicates a relatively productive/poor forage production month, respectively. Multiplying PI by average monthly forage production as a percent of total annual yield, weather-induced impacts on forage production could be estimated. Note that increased fertilizer application leads to increased monthly forage production that in turn is affected by the production

\footnotetext{
${ }^{2}$ Fewer than $2 \%$ of observations were missing likely because of snow cover as they occurred in December, January, February, and April. Missing observations were assigned a value of 1 , meaning monthly average forage growth was assumed for missing observations.
} 
index for simulation of weather effects. The monthly default distribution of forage production used in FORCAP (Tables 2 and 3) is based on expert opinion of John Jennings (range management specialist, University of Arkansas Cooperative Extension Service, personal communication, 2013) and Charles West (Thornton Distinguished Chair, Forage Systems Research, Texas Tech University, personal communication, 2013) and is similar to values found in Gadberry (2015) and Huneycutt, West, and Phillips (1988). Adding weather effects by using the production index, a modification to FORCAP, affected grazing capacity and the attendant need to supplement herd nutrition requirements with hay and corn as shown in Tables 2 and 3 for 2004 as an example. In turn, hay sales or purchases were a result of on-farm hay production on both hay land and pastures and the amount of hay fed to the herd. Weather effects on ability to harvest hay (e.g., excessively wet conditions could preempt harvest) were not addressed.

Monthly variability in the forage PI values by select years from 1990 to 2014 demonstrates how forage production was affected on a monthly basis (Figure 1). As mentioned earlier, 2012 was a drought year that affected summer forage availability nationwide and also on the fields analyzed here. However, early spring and late fall conditions for forage production were above average in 2012. Forage production in 2004, by contrast, only had one above average forage PI value in July. Figure 1 thus demonstrates the amount of risk cow-calf producers face in terms of forage and hay availability with direct implications for cow-calf profitability as FORCAP automatically supplements with hay and corn when nutrition requirements are not met by forages growing on pasture and hay land.

\subsection{Baseline model parameters}

For each level of fertilizer use, a baseline set of parameters was used to resemble a fall or spring calving, Arkansas cow-calf operation. This baseline used 80 acres of hay land and 320 acres of pasture that was rotationally grazed to allow the producer to harvest excess forage from pasture when available. Additionally, 80 acres of winter wheat was sod seeded yearly on pasture in the fall for graze out in spring months to model forage production of winter annuals in FORCAP. Fertilizer application was varied and described in Table 4. As is common in northwest Arkansas, pasture forage species consisted of $25 \%$ Bermuda grass, $65 \%$ fescue, and $10 \%$ clover by area. Hay forage species consisted of $50 \%$ Bermuda grass, $45 \%$ fescue, and $5 \%$ clover by area. Forage production for a species was thus calculated as acres in production multiplied by annual grazing potential of a pure stand of the species. This calculation was then adjusted by month for seasonal forage availability and was further adjusted by weather effects if desired. FORCAP defaults were used for mature/young cow weights, birth weight, weaning weight, and age. When necessary, FORCAP calculates supplemental feed needs in the form of corn and hay to ensure adequate crude protein and total digestible nutrient intake for maintaining cow body condition. The fall calving season (October) was selected to enhance breeding success compared with spring calving (April) when fescue toxicosis leads to a greater likelihood of breeding failure (Caldwell et al., 2013). One herd sire was utilized for every 30 cows. Therefore, for the two observed cattle cycles, 100-cow herd operations with least or intermediate fertilizer use required four herd sires, while highest fertilizer use with 160 cows required six herd sires. Over the cattle cycle, five revenue streams were available annually and included the sale of (1) weaned steer calves, (2) weaned heifer calves, (3) cull cows, (4) cull herd sires, and (5) excess hay produced on farm.

Cattle sale prices were monthly Arkansas average prices for medium and large frame No. 1 steer and heifer calves, breaking utility and commercial (75\%-80\% lean) cows, and yield grade 1-2 (1,100-2,100 lb.) bulls as provided by USDA's Agricultural Marketing Service. Monthly observations added the possibility to adjust cattle revenue by seasonal timing of sales dictated by calving season chosen. Price data not related to cattle, in part driven by supply uncertainties and time of transaction in a particular year, were annual, Arkansas prices given data availability for hay, corn, fertilizer, fertilizer application costs, seed cost for winter annuals, and diesel fuel for 
1990-2014 (Figure 2). For fertilizer and fuel prices, data were gathered from USDA-NASS (2014) for 1990-2008 and from Mississippi State University (2014) for 2009-2014. Hay and feed prices were collected from USDA-NASS (2014). When data were not readily available for these inputs, similar inputs with available price data were used to estimate a value for that year (Tester, 2017).

\subsection{Herd sire and calving management}

All 100-cow scenarios began with a herd consisting of 83 mature cows and 17 young cows that were exposed to the herd sires each year. Eighteen replacement heifers were needed for herd replenishment given 1 cow death loss. All 160-cow scenarios began with a herd consisting of 133 mature cows and 27 young cows. Twenty-nine replacement heifers were held back to replace cull animals and 2 cow death losses. All cows and heifers were assumed to be bred in January and July of each year for the fall and spring calving herds, respectively. Heifers were bred at 15 months of age to calve for the first time at 24 months of age. Culling and heifer retention decisions were made in May and November of each year for fall and spring calving herds, respectively, and occurred at the same time calves were weaned and sold. One-sixth of the breeding herd was culled yearly based on the expectation of weaning six calves from a cow over its useful life. Cows that were open as a result of breeding failure were also culled. The FORCAP default rate of $6 \%$ and $20 \%$ breeding failures was used for fall and spring calving herds, respectively. Regardless of calving season, cow and calf death losses were set to $1 \%$ and 3\%, respectively (Ritchie and Anderson, 1994; Smith et al., 2012). The number of replacement heifers needed to maintain the herd size was thus a result of cull cows sold, either because of age or for being open, and cow death losses. FORCAP v.2 2014 was modified to allow retention numbers to be manipulated by the user to grow or shrink the herd from year to year. A separate model run was performed each year, by HSM strategy, fertilizer application rate, calving season, and inclusion or exclusion of weather effects. A total of 1,800 annual herd performance measures were collected, which included cash operating profit, hay sold, and head sold as estimated in FORCAP.

\subsection{Herd size changes across herd size management strategies}

The CHS strategy simulates a producer who does not change herd size despite changing weather and cattle prices as hay and corn were considered available for purchase as needed. This strategy was considered the least management intensive.

For the countercyclical MA strategy, the simulation assumes the same starting herd size as the CHS strategy. However, herd size subsequently grows or declines given heifer retention decisions that are based on the price ratio of 10- to 27-month MA steer prices at the time of breeding each year (January and July, for fall and spring calving herds, respectively). A price ratio above 1 signals the sale of added heifer calves to reduce herd size in anticipation of eventual downward pressure on prices when otherwise retained heifers would lead to added weaned calf sales. A price ratio below 1 signals herd expansion in anticipation of an eventual upward trend in prices. For both signals, 2 or 3 additional heifers, pending 100- or 160-cow herd size, respectively, are sold or added in comparison with maintaining the herd at the size of the prior year. Prices for steers were used for signals, as they make up the majority of cattle sales (Table 1). The 27-month period was chosen as a second rebreeding of retained heifers would occur at that time and the shorter-term, 10-month period captures the time period from the start of breeding to calving with an average 1-month period for breeding. Using a larger increment or decrement for extra heifers to retain was not undertaken in this study as herd sire needs would change over time.

The DCA strategy uses constant yearly dollar reinvestment in the herd. Low/high heifer prices led to herd expansion/contraction, respectively, using nominal prices. Yearly herd reinvestment was determined by finding the value of an $800-\mathrm{lb}$. heifer in the herd size adjustment or calf sale 
month (equation 3) and multiplying by the number of replacement heifers needed based on herd size (equation 4). These annual reinvestment values were then averaged across cycles (1990-2003 and 2004-2014) to find the target constant yearly average dollar reinvestment (equation 5) needed to determine the annual number of replacement heifers to retain given that year's replacement heifer value (equation 6) as follows:

$$
\begin{gathered}
P R H_{j s}=P H_{j s} \cdot 8 \quad j=1990-2014 \text { and }\left\{\begin{array}{l}
s=\text { May } \forall \text { fall calving herds } \\
s=\text { November } \forall \text { spring calving herds }
\end{array}\right. \\
R_{j s l}=P R H_{j s} \cdot l\left\{\begin{array}{l}
l=18 \forall 100 \text {-cowscenarios } \\
l=29 \forall 160 \text {-cowscenarios }
\end{array}\right. \\
\overline{R_{s l k}}=\sum_{j_{k}} R_{j s l} / Y_{k}\left\{\begin{array}{l}
\forall j_{k}=1990-2003 \text { where } Y_{k}=14, \text { or } \\
\forall j_{k}=2004-2014 \text { where } Y_{k}=11
\end{array},\right. \\
Q R H_{j s l k}=\bar{R}_{s l k} / P R H_{j s} \text { rounded to the nearest head, }
\end{gathered}
$$

where $j$ again represents a year in the cattle cycle; $P R H_{j s}$ was the yearly value of an $800-\mathrm{lb}$. replacement heifer in $\$ /$ head by calving season and $s ; P H_{j s}$ was the annual price of a 700 - to $800-1 b$. heifer in $\$ /$ cwt.; $R_{j s l}$ represents the value of replacement heifers given $l$ head of replacement heifer needs associated with 100 - or 160 -cow herd sizes; $\overline{R_{s l k}}$ is the average yearly reinvestment that depends on calving season and herd size over the analyzed period, $k$; and $Q R H_{j s l k}$ is the annual number of heifers retained by year, calving season, LUI, and period analyzed. For the 25-year analysis, the same herd sizes as in each cycle were used except for 2003 when heifer retention returned the herd to 100 or 160 cows for the start of the second cycle.

\subsection{Analysis}

Cash operating profit risk over time was analyzed using box and whisker plots for each HSM strategy for each LUI, with and without simulated weather effects, by calving season, and for each cattle cycle or time period. Rather than developing a model that selects the optimal producer choice in terms of cash operating profit, given an array of risk aversion levels, the reader is thus expected to visually assess the inherent risk differences across the management options presented.

Aside from annual cash operating profits, the number of bales of hay and cattle sold provided insight about the primary sources of revenue for a HSM strategy $\times$ LUI combination. Hay and head sold describe performance implications of management choices in terms of physical production units rather than in dollar terms.

Finally, profits were examined using the minimum regret rule. Regret was calculated using net present value (NPV) of annual cash operating profits across the entire cattle cycle(s) to account for inflation and risk. Regret was defined as the loss a producer would have incurred over the course of a cattle cycle(s) as a result of choosing a suboptimal HSM strategy for a particular LUI. Regret was calculated for each cattle cycle(s), with and without simulated weather effects, and by calving season and was termed HSM regret. Regret numbers thus quantify differences across the HSM options evaluated. These regret numbers easily allowed for assessment of consistency of HSM strategy choice across periods analyzed and/or whether simulated weather effects were included or not. Also calculated were regret values for the choice of LUI pursued within a given HSM strategy. Again, these numbers were calculated by cattle cycle(s) and weather effects combinations and were termed LUI regret. NPV was calculated using a nominal discount rate of 8\% (Hardie, 1984) that reflected common, agricultural lending rates over the period analyzed. ${ }^{3}$

\footnotetext{
${ }^{3}$ Higher and lower interest rates of $10 \%$ and $5 \%$, respectively, led to similar results.
} 


\section{Results}

Described subsequently are herd size changes as a function of the chosen HSM strategy followed by a discussion on attendant profitability and risk implications by calving season in order of cattle cycle(s). Effects of weather on risk and profitability are discussed throughout.

\subsection{Herd size fluctuations}

Breeding herd size changes over time for operations starting with 100 cows are shown in Figure 3. For the 1990-2003 cycle, the MA strategy had the largest herd in 1998, while the DCA strategy peaked at a higher level in 1997 and led to greatest total cattle output when compared with the other two HSM strategies. During this cycle, the lowest cattle prices were encountered in 1996 (Figure 2) and led to noticeably rapid herd size expansion for the DCA strategy in particular. In comparison with the CHS strategy, both the MA and DCA strategies had larger overall average herd sizes when cattle prices were on the rise (Figures 2 and 3).

For the second cattle cycle, the DCA and MA strategies led to more pronounced differences in herd size changes over time (Figure 3). The MA strategy led to 3 years of herd reduction followed by 4 years of expansion before reverting back to 3 more years of reduction to end the cycle. The DCA strategy steadily expanded the herd until 2012 when further retention was too costly given high cattle prices.
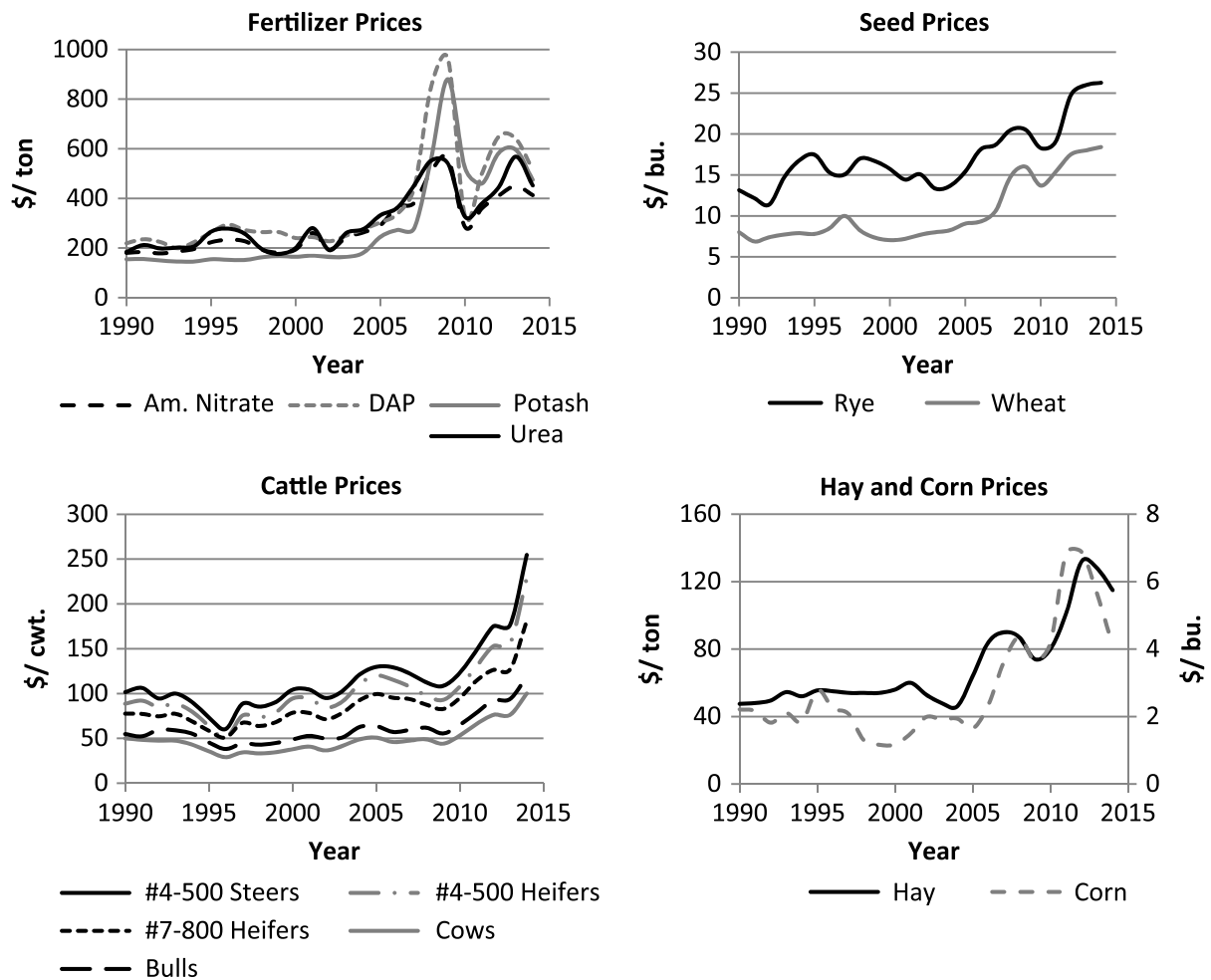

Figure 2. Nominal prices for major input and output prices, 1990-2014. Notes: Only one weight category of calf prices is exhibited because of calf prices by weight category moving in a similar direction over time. The 700- to 800 -lb. heifer prices are shown as a reference for heifer replacement costs. Cattle prices shown are annual averages but are higher for fall calving operations than spring calving operations once adjusted for monthly seasonal differences. Am. Nitrate, ammonium nitrate; DAP, diammonium phosphate. 
First Cattle Cycle (1990-2003)
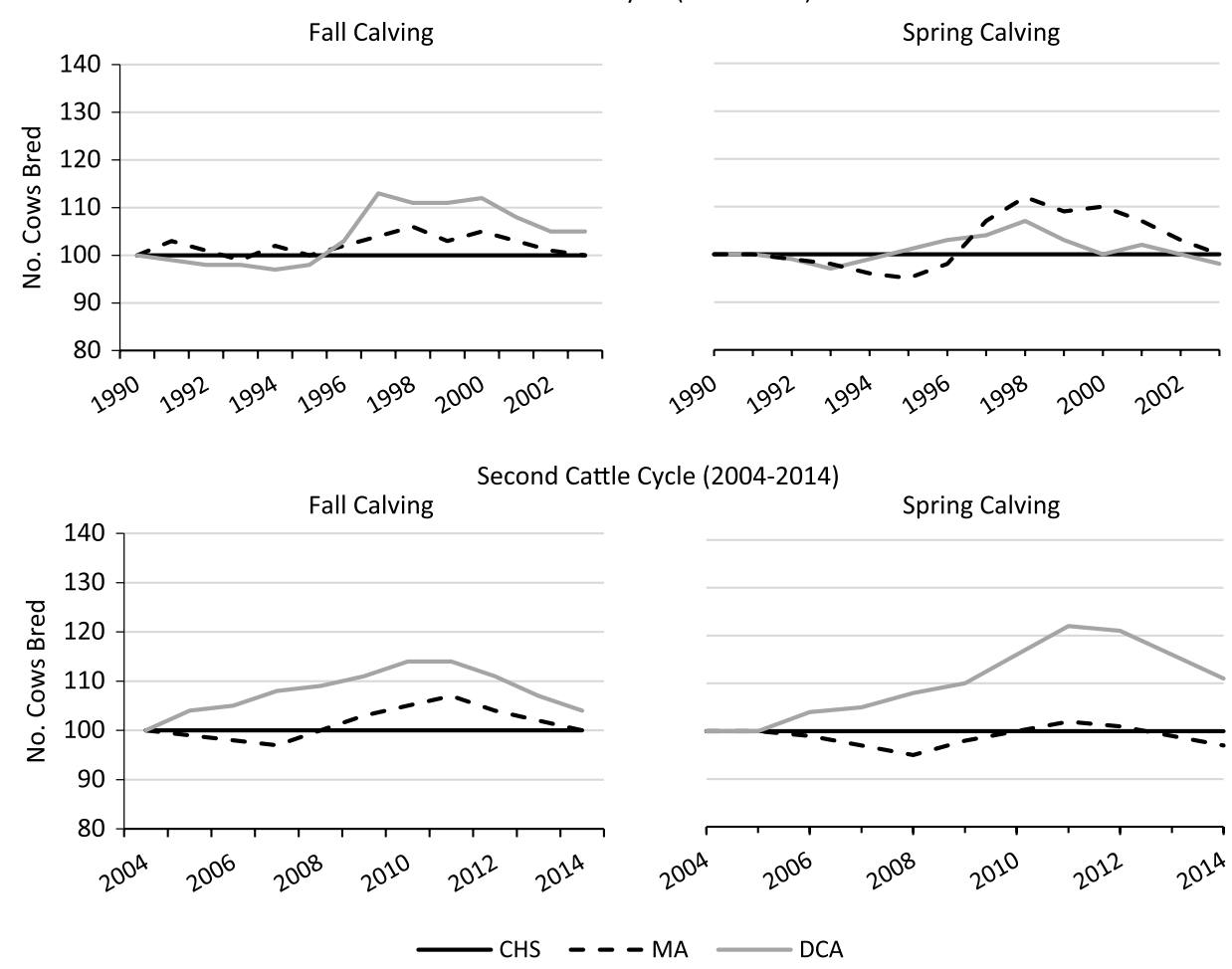

Figure 3. Breeding herd sizes by strategy and period analyzed for fall and spring calving herds. Notes: The constant herd size (CHS) strategy led to no change in cow herd size. The moving average (MA) strategy used a ratio of two MAs of feeder steer prices to signal an up- or downtrend in cattle prices with herd expansion/liquidation on downtrend/uptrend signal. The dollar cost averaging (DCA) strategy as described in equations (3)-(6) kept replacement heifer investment constant over time. The 160 -cow herd sizes are not shown as same trends were evident.

Because the DCA strategy maintained the largest herd throughout the observed periods, this strategy consistently yielded the lowest hay sold and the highest number of head sold (Tables 5 and 6). Although achieving the goal of selling more cattle during the period of high cattle prices, lower hay sales and/or greater hay purchases more than offset added cattle revenue.

\subsection{Fall calving}

For the 1990-2003 cycle, our results indicated that the addition of weather effects on forage production increased risk in terms of range (maximum-minimum) of annual cash operating profit $(\pi)$ regardless of LUI or HSM strategy (Figure 4). Additionally, increased LUI decreased profitability regardless of HSM strategy because added capital recovery charges $(\sim \$ 3,500)$ and property taxes for added cattle summed to nearly $\$ 3,800$ per year. Table 5 added these costs in the larger breeding herd strategy outcomes with highest LUI. According to LUI regret, least fertilizer use was the profit-maximizing choice in the first cycle in the absence of weather effects for all HSM strategies. Once weather effects were included, profit-maximizing LUI increased to medium for CHS and MA, whereas for DCA, least fertilizer use was profit maximizing. With least fertilizer use, including weather effects led to hay purchases on average for the DCA strategy. For all HSM strategies, hay sales were lower on average and exhibited much larger variation in part because of different cattle output, but also because of changes in forage production when weather effects were included. Choosing medium LUI as profit maximizing, the MA strategy emerged as the least HSM 
Table 5. Performance statistics for fall calving herds by weather effects, cattle cycle(s), land use intensity (LUI) and herd size management (HSM) strategy

\begin{tabular}{|c|c|c|c|c|c|c|c|c|c|c|c|}
\hline \multirow[b]{3}{*}{ Period } & \multicolumn{2}{|c|}{ LUI $^{\mathrm{a}}$} & \multicolumn{3}{|c|}{ Low } & \multicolumn{3}{|c|}{ Medium } & \multicolumn{3}{|c|}{ High } \\
\hline & \multirow[b]{2}{*}{ Performance Metric } & \multirow[b]{2}{*}{ Weather Effects } & \multicolumn{9}{|c|}{ HSM Strategy $^{\mathrm{b}}$} \\
\hline & & & $\mathrm{CHS}$ & MA & DCA & $\mathrm{CHS}$ & MA & DCA & $\mathrm{CHS}$ & MA & DCA \\
\hline \multirow[t]{9}{*}{$1990-2003$} & NPV of $\pi^{c}$ & Excl. & 45.0 & $46.3^{d}$ & 45.0 & 41.0 & 43.1 & 42.7 & -1.6 & -4.4 & -3.5 \\
\hline & & Incl. & 35.9 & 38.2 & 38.9 & 37.6 & 38.7 & 37.9 & -6.2 & -10.6 & -9.3 \\
\hline & HSM regret ${ }^{\mathrm{e}}$ & Excl. & 13.0 & 0.0 & 12.9 & 20.9 & 0.0 & 4.0 & 0.0 & 28.0 & 19.0 \\
\hline & & Incl. & 31.0 & 7.9 & 0.0 & 10.9 & 0.0 & 8.6 & 0.0 & 43.6 & 31.3 \\
\hline & No. hay bales sold ${ }^{f}$ & Excl. & $49(0)$ & $22(20)$ & $3(61)$ & $171(0)$ & $148(18)$ & $129(55)$ & $46(0)$ & $8(25)$ & $-10(98)$ \\
\hline & & Incl. & $36(146)$ & $6(140)$ & $-9(131)$ & $168(157)$ & $140(150)$ & $127(146)$ & $56(222)$ & $13(207)$ & $-11(196)$ \\
\hline & Head sold & Either & $90(0)$ & $93(3)$ & $94(7)$ & $90(0)$ & $93(3)$ & $94(7)$ & $146(0)$ & $148(5)$ & $150(11)$ \\
\hline & LUI regret ${ }^{\mathrm{g}}$ & Excl. & 0.0 & 0.0 & 0.0 & 39.9 & 32.1 & 23.2 & 466.3 & 507.3 & 485.4 \\
\hline & & Incl. & 17.7 & 5.6 & 0.0 & 0.0 & 0.0 & 10.9 & 438.3 & 492.9 & 482.9 \\
\hline \multirow[t]{9}{*}{ 2004-2014 } & NPV of $\pi$ & Excl. & 133.1 & 136.3 & 132.2 & 147.4 & 151.4 & 151.2 & 133.6 & 136.3 & 126.2 \\
\hline & & Incl. & 131.2 & 135.4 & 131.8 & 135.3 & 153.6 & 137.7 & 138.9 & 138.2 & 128.6 \\
\hline & HSM regret & Excl. & 32.3 & 0.0 & 40.8 & 39.9 & 0.0 & 2.2 & 27.2 & 0.0 & 100.7 \\
\hline & & Incl. & 42.0 & 0.0 & 36.7 & 182.5 & 0.0 & 158.5 & 0.0 & 6.8 & 102.9 \\
\hline & Hay sold & Excl. & $49(0)$ & $33(33)$ & $-36(46)$ & $171(0)$ & $157(28)$ & $95(42)$ & $46(0)$ & $44(48)$ & $-76(72)$ \\
\hline & & Incl. & $40(102)$ & $26(94)$ & $-42(80)$ & $171(100)$ & $150(92)$ & $89(74)$ & $61(142)$ & $48(136)$ & $-72(113)$ \\
\hline & Head sold & Either & $90(0)$ & $92(4)$ & $98(6)$ & $90(0)$ & $92(4)$ & $98(6)$ & $146(0)$ & $147(6)$ & $157(8)$ \\
\hline & LUI regret & Excl. & 143.5 & 151.1 & 189.7 & 0.0 & 0.0 & 0.0 & 138.4 & 151.2 & 249.8 \\
\hline & & Incl. & 76.2 & 181.4 & 59.6 & 35.3 & 0.0 & 0.0 & 0.0 & 153.9 & 91.6 \\
\hline
\end{tabular}


Table 5. (Continued)

\begin{tabular}{|c|c|c|c|c|c|c|c|c|c|c|c|}
\hline \multirow[b]{3}{*}{ Period } & \multicolumn{2}{|c|}{ LUI $^{\mathrm{a}}$} & \multicolumn{3}{|c|}{ Low } & \multicolumn{3}{|c|}{ Medium } & \multicolumn{3}{|c|}{ High } \\
\hline & \multirow[b]{2}{*}{ Performance Metric } & \multirow[b]{2}{*}{ Weather Effects } & \multicolumn{9}{|c|}{ HSM Strategy ${ }^{b}$} \\
\hline & & & $\mathrm{CHS}$ & MA & DCA & $\mathrm{CHS}$ & MA & DCA & $\mathrm{CHS}$ & MA & DCA \\
\hline \multirow[t]{9}{*}{$1990-2014$} & NPV of $\pi$ & Excl. & 90.3 & 93.5 & 90.7 & 91.2 & 95.4 & 94.8 & 43.8 & 43.1 & 40.3 \\
\hline & & Incl. & 76.1 & 78.9 & 77.4 & 83.1 & 85.9 & 84.4 & 32.7 & 29.0 & 26.8 \\
\hline & HSM regret & Excl. & 32.5 & 0.0 & 28.4 & 42.5 & 0.0 & 6.3 & 0.0 & 7.7 & 35.9 \\
\hline & & Incl. & 27.4 & 0.0 & 14.6 & 28.4 & 0.0 & 15.5 & 0.0 & 37.1 & 59.0 \\
\hline & Hay sold & Excl. & $49(0)$ & $33(33)$ & $-36(46)$ & $171(0)$ & $157(28)$ & $95(42)$ & $46(0)$ & $44(48)$ & $-76(72)$ \\
\hline & & Incl. & $38(149)$ & $16(145)$ & $-24(126)$ & $170(156)$ & $148(152)$ & 107(132) & $58(216)$ & $28(210)$ & $-38(175)$ \\
\hline & Head sold & Either & $90(0)$ & $93(4)$ & $96(7)$ & $90(0)$ & $93(4)$ & $96(7)$ & $146(0)$ & $147(6)$ & $157(8)$ \\
\hline & LUI regret & Excl. & 8.9 & 19.0 & 41.0 & 0.0 & 0.0 & 0.0 & 473.5 & 523.6 & 545.5 \\
\hline & & Incl. & 69.6 & 70.5 & 69.5 & 0.0 & 0.0 & 0.0 & 503.3 & 568.8 & 575.1 \\
\hline
\end{tabular}

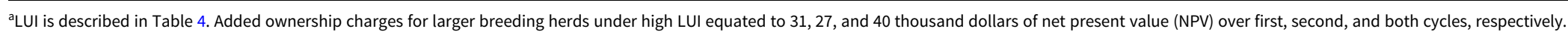

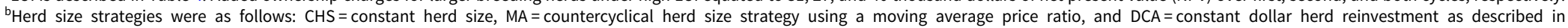
equations (3)-(6).

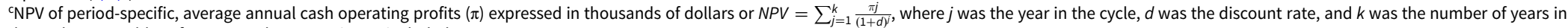
the cycle. See Table 1 for cost and revenue items included.

dBoldface indicates optimal HSM strategy choices on the basis of highest NPV of $\pi$ for a particular LUI level $\times$ period $\times$ weather effects combination.

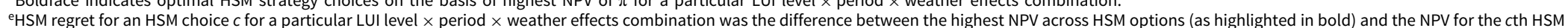
option. Regret was expressed in hundreds of dollars, and zero regret identified the profit-maximizing HSM strategy for a particular LUI level $\times$ period $\times$ weather effects combination.

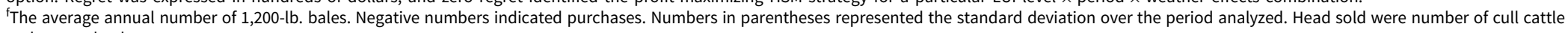
and weaned calves.

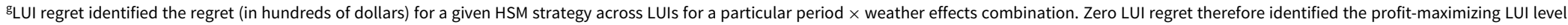

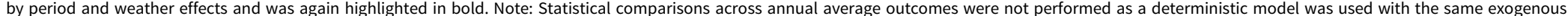
price and weather data across herd size strategy $\times$ LUI outcomes. 
Table 6. Performance statistics for spring calving herds by weather effects, cattle cycle(s), land use intensity (LUI) and herd size management (HSM) strategy.

\begin{tabular}{|c|c|c|c|c|c|c|c|c|c|c|c|}
\hline \multirow[b]{2}{*}{ Period } & \multicolumn{2}{|c|}{$\mathrm{LUI}^{\mathrm{a}}$} & \multicolumn{4}{|c|}{ Low } & \multicolumn{3}{|c|}{ Medium } & \multicolumn{2}{|c|}{ High } \\
\hline & Performance Metric & Weather Effects & $\mathrm{CHS}$ & MA & DCA & $\mathrm{CHS}$ & MA & DCA & $\mathrm{CHS}$ & MA & DCA \\
\hline \multirow[t]{9}{*}{ 1990-2003 } & NPV of $\pi^{c}$ & Excl. & -7.5 & $-17.7^{d}$ & -13.8 & -9.0 & -18.1 & -14.6 & -95.5 & -104.9 & -102.4 \\
\hline & & Incl. & -13.3 & -22.4 & -19.5 & -14.8 & -24.0 & -20.3 & -104.2 & -113.6 & -110.8 \\
\hline & HSM regret ${ }^{\mathrm{e}}$ & Excl. & 0.0 & 102.2 & 63.2 & 0.0 & 90.8 & 56.2 & 0.0 & 93.8 & 68.9 \\
\hline & & Incl. & 0.0 & 90.4 & 61.4 & 0.0 & 91.8 & 54.3 & 0.0 & 94.2 & 66.6 \\
\hline & No. hay bales sold & Excl. & $87(0)$ & $52(46)$ & $44(68)$ & $221(0)$ & $191(41)$ & $180(66)$ & $119(0)$ & $79(56)$ & $43(107)$ \\
\hline & & Incl. & $75(147)$ & $46(142)$ & $34(137)$ & 205(159) & $176(158)$ & $166(150)$ & $105(223)$ & $66(220)$ & $28(217)$ \\
\hline & Head sold & Either & $78(0)$ & $78(4)$ & $80(7)$ & $78(0)$ & $78(4)$ & $80(7)$ & $124(0)$ & $125(6)$ & $128(12)$ \\
\hline & LUI regret & Excl. & 0.0 & 0.0 & 0.0 & 14.9 & 3.5 & 7.9 & 899.9 & 891.5 & 905.6 \\
\hline & & Incl. & 0.0 & 0.0 & 0.0 & 15.1 & 16.5 & 8.0 & 908.3 & 912.0 & 913.6 \\
\hline \multirow[t]{9}{*}{ 2004-2014 } & NPV of $\pi$ & Excl. & 74.4 & 71.4 & 51.7 & 92.7 & 90.7 & 72.7 & 29.5 & 28.1 & -2.5 \\
\hline & & Incl. & 71.8 & 70.7 & 50.9 & 91.0 & 89.5 & 73.4 & 27.4 & 27.4 & -1.7 \\
\hline & HSM regret & Excl. & 0.0 & 30.7 & 227.2 & 0.0 & 19.7 & 199.2 & 0.0 & 13.6 & 320.0 \\
\hline & & Incl. & 0.0 & 10.8 & 209.0 & 0.0 & 15.5 & 176.6 & 0.0 & 0.0 & 290.9 \\
\hline & Hay sold & Excl. & $87(0)$ & $84(35)$ & $-50(78)$ & $221(0)$ & $222(29)$ & $86(78)$ & $119(0)$ & $127(48)$ & $-94(118)$ \\
\hline & & Incl. & $76(93)$ & $79(93)$ & $-58(64)$ & $212(101)$ & $213(100)$ & $82(75)$ & $111(140)$ & $124(159)$ & $-98(141)$ \\
\hline & Head sold & Either & $78(0)$ & $77(3)$ & $86(10)$ & $78(0)$ & $77(3)$ & $86(10)$ & $124(0)$ & $122(5)$ & $137(17)$ \\
\hline & LUI regret & Excl. & 182.3 & 193.3 & 210.3 & 0.0 & 0.0 & 0.0 & 631.9 & 625.8 & 752.8 \\
\hline & & Incl. & 192.2 & 187.5 & 224.6 & 0.0 & 0.0 & 0.0 & 636.4 & 620.8 & 750.6 \\
\hline
\end{tabular}


Table 6. (Continued)

\begin{tabular}{|c|c|c|c|c|c|c|c|c|c|c|c|}
\hline \multirow[b]{2}{*}{ Period } & \multicolumn{2}{|c|}{ LUI $^{\mathrm{a}}$} & \multicolumn{4}{|c|}{ Low } & \multicolumn{3}{|c|}{ Medium } & \multicolumn{2}{|c|}{ High } \\
\hline & Performance Metric & Weather Effects & $\mathrm{CHS}$ & MA & DCA & $\mathrm{CHS}$ & MA & DCA & $\mathrm{CHS}$ & MA & DCA \\
\hline \multirow[t]{9}{*}{$1990-2014$} & NPV of $\pi$ & Excl. & 17.8 & 6.6 & 3.0 & 22.5 & 12.8 & 9.4 & -85.5 & -94.6 & -103.0 \\
\hline & & Incl. & 5.6 & -3.7 & -7.9 & 10.4 & 1.1 & -1.4 & -102.2 & -112.4 & -118.1 \\
\hline & HSM regret & Excl. & 0.0 & 112.6 & 147.8 & 0.0 & 97.5 & 131.4 & 0.0 & 91.2 & 175.4 \\
\hline & & Incl. & 0.0 & 92.7 & 134.8 & 0.0 & 92.5 & 118.1 & 0.0 & 101.7 & 158.5 \\
\hline & Hay sold & Excl. & $87(0)$ & $66(45)$ & $3(86)$ & $221(0)$ & $204(39)$ & $138(85)$ & $119(0)$ & $99(57)$ & $-19(130)$ \\
\hline & & Incl. & $78(147)$ & $64(150)$ & $-5(112)$ & $206(156)$ & 192(163) & $129(127)$ & $109(211)$ & $88(227)$ & $-27(185)$ \\
\hline & Head sold & Either & $78(0)$ & $78(4)$ & $82(9)$ & $78(0)$ & $78(4)$ & $82(9)$ & $124(0)$ & $124(5)$ & $132(15)$ \\
\hline & LUI regret & Excl. & 47.2 & 62.3 & 63.6 & 0.0 & 0.0 & 0.0 & $1,080.3$ & 912.4 & $1,030.4$ \\
\hline & & Incl. & 48.1 & 48.3 & 64.9 & 0.0 & 0.0 & 0.0 & $1,126.1$ & $1,135.3$ & $1,166.5$ \\
\hline
\end{tabular}

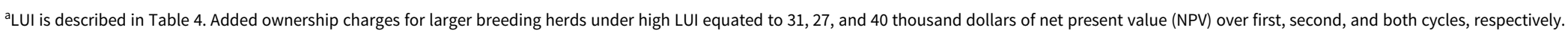

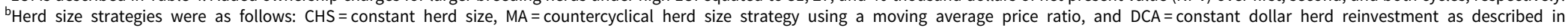
equations (3)-(6).

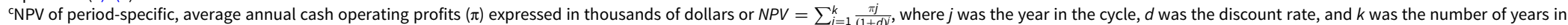
the cycle. See Table 1 for cost and revenue items included.

dBoldface indicated optimal HSM strategy choices on the basis of highest NPV of $\pi$ for a particular LUI level $\times$ period $\times$ weather effects combination.

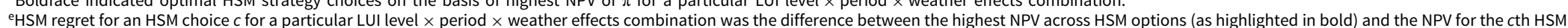
option. Regret was expressed in thousands of dollars, and zero regret identified the profit-maximizing HSM strategy for a particular LUI level $\times$ period $\times$ weather effects combination.

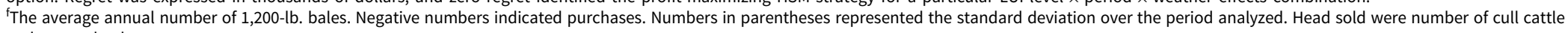
and weaned calves.

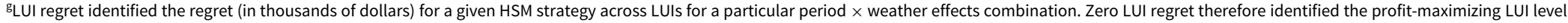

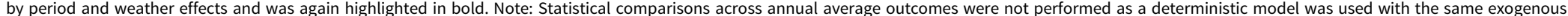
price and weather data across herd size strategy $\times$ LUI outcomes. 
regret choice regardless of weather effects. Choosing least fertilizer use, the MA strategy was profit maximizing without weather effects, and the DCA strategy was profit maximizing when weather was included. Finally, range of $\pi$ was highest with highest fertilizer use.

During the second cycle, the range in $\pi$ did not increase with the addition of weather (Figure 4) regardless of LUI. Nonetheless, the distance from the $25^{\text {th }}$ to $75^{\text {th }}$ percentile observations increased. Given the observation of lesser range in $\pi$ for the second cycle compared with the first, weather had a lesser effect on income variability. This change in weather effects on income variability was, in part, a function of the period-specific adjustment effects on forage production. As shown in Figure 1, forage production index values during winter months showed forage production to be lower than the longterm average in the second cycle, whereas forage production was higher than the long-term average in the first cycle. In slight contrast to the previous cycle, $\pi$ increased with greater LUI regardless of HSM strategy as hay prices were high enough to offset heightened input cost by selling excess hay (Figure 2). For the management option with greatest fertilizer use and added cattle sales, added cost of fertilizer and added ownership charges for extra breeding herd investment could not be offset except using CHS in the scenario with weather effects. Hence, medium fertilizer use had least LUI regret, and at that level of fertilizer use, NPV of $\pi$ was highest for MA regardless of weather. Finally, as shown in Figure 4, the high LUI choice showed the greatest range in $\pi$.

As expected, results for both cycles, spanning production years 1990-2014, exhibited similar trends as observed across each cycle individually. Range of $\pi$ increased with the addition of weather, as expected, regardless of HSM strategy or LUI (Figure 4). As LUI increased, NPV of $\pi$ increased for the 100-cow herds and subsequently fell for the 160-cow herd (Table 5). As such, the medium fertilizer option was profit-maximizing given zero LUI regret across all HSM options. Medium LUI also exhibited approximately the same level of income risk as the low LUI option (Figure 4). At that level of fertilizer use, the MA strategy showed least HSM regret regardless of weather (Table 5). When taking profit-maximizing LUI choice into account for each period of analysis, the addition of weather for the longest run did not affect HSM strategy choice, which was different from the results for the previous two cycles.

Given the objective of examining long-term impact of weather and time period on management choices, ${ }^{4}$ it was noticeable that the size of HSM regret values over the 25 -year period was quite small. Choosing CHS, the least management-intensive HSM option, with medium fertilizer use and assuming that weather simulation was reasonable, for example, led to a regret of only $\$ 2,840$ dollars over 25 years and even less when using least fertilizer. There are differences across cycles as discussed previously, and adding weather effects increased income risk as uncertain forage production led to changes in sales above and beyond variation caused by changes in cattle prices and number of head sold. Nonetheless, HSM regret values did not consistently increase or decrease when weather effects were added for comparisons within individual LUI $\times$ cattle cycle combinations. Under low LUI in the first cycle, for example, regret increased for the CHS choice when weather was added, whereas it declined for the same cycle with medium fertilizer use. As such, and as might be expected, weather played an uncertain role as to what HSM strategy to pursue. The same can be said for cattle cycle impacts on HSM strategy choice.

\subsection{Spring calving}

Similar to fall calving, adding weather effects on forage production for spring calving operations increased range in $\pi$, as did an increase in stocking rate (Figure 5). Also, for the period 1990-2003, the CHS strategy was dominant in terms of HSM regret regardless of LUI (Table 6) and by more

\footnotetext{
${ }^{4}$ It is cost prohibitive for a producer to change calving season from year to year. As such, calving season choice is a longterm decision. Also, fertilizer use decisions, although annually flexible, are complex as weather conditions can affect fertilizer productivity (e.g., applying fertilizer before a drought is ineffective as is a killing frost in late spring or early fall). Hence, the LUI choice is considered a long-term decision, especially in the scenario where the breeding herd is expanded.
} 


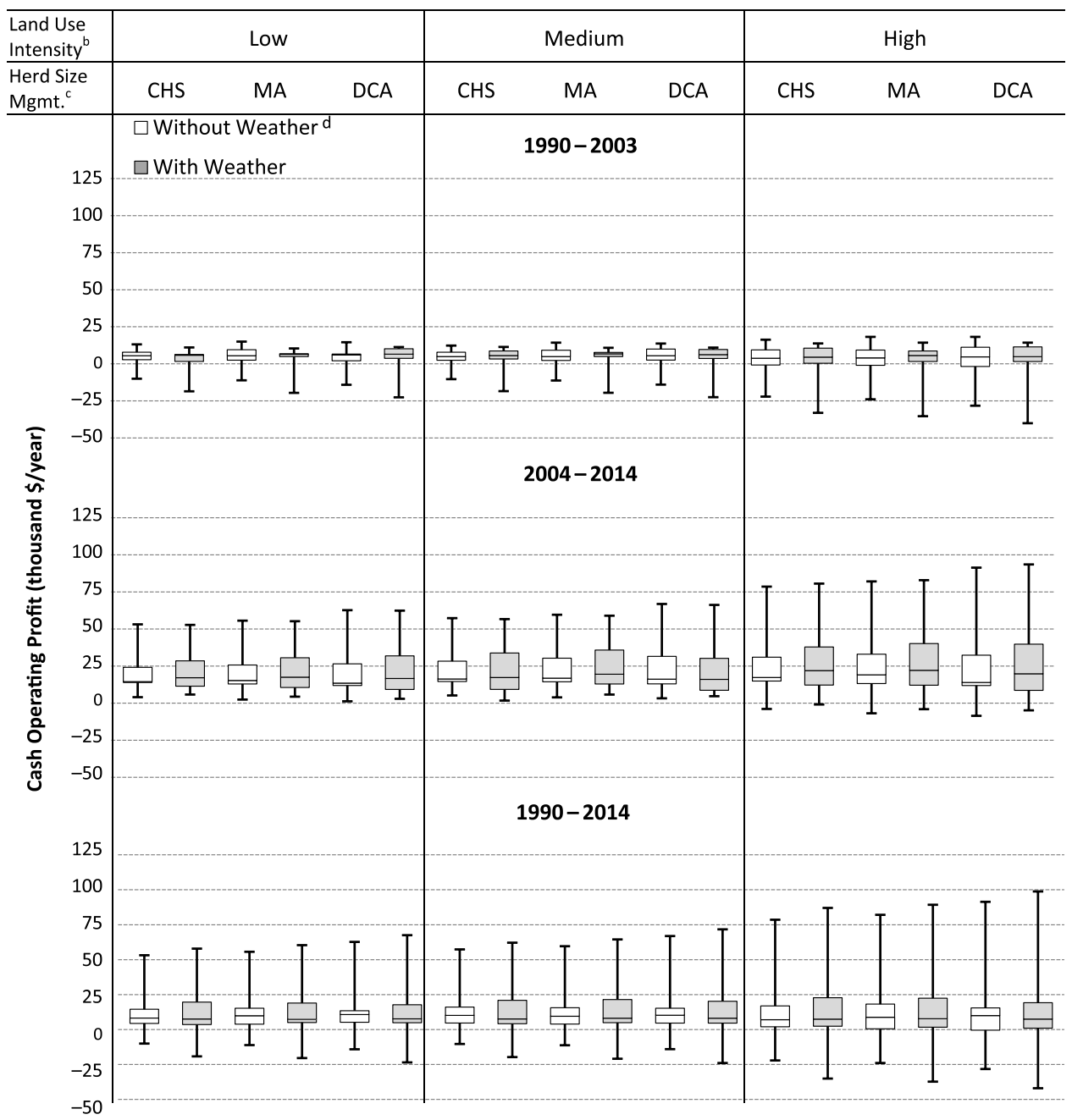

Figure 4. Minimum, median, maximum, and $25^{\text {th }}$ and $75^{\text {th }}$ percentiles of cash operating profit ${ }^{\text {a }}$ for fall calving herds by land use intensity, herd size management strategy, and cattle cycle or time period with weather effects excluded and included. ${ }^{a}$ Cash operating profits were period-specific and were calculated as the sale of cattle and excess hay less costs for feed and supplements, seed, fuel, fertilizer, twine, chemicals, veterinary services, operating interest, repairs, and medicine in $\$ / y e a r$. ${ }^{b}$ Land use intensity is described in Table $1 .{ }^{c}$ Herd size strategies were as follows: CHS = constant herd size cow herd size, $M A=$ cow herd size strategy using a ratio of two moving averages of feeder steer prices to signal an up- or downtrend in cattle prices, and DCA = dollar cost averaging strategy as described in equations (3)-(6). ${ }^{d}$ See Figure 1 for production index adjustment because of weather conditions.

compelling regret amounts in comparison with numbers presented for fall calving in Table 5 for the same cycle. Compared with fall calving, increased breeding failure rate led to less income as was already demonstrated for a sample year in Table 1 . Adding weather uncertainty weakened profitability as hay sales declined along with added variation in forage production (Table 6). In contrast with fall calving, hay sales were higher given different seasonal nutrition needs as demonstrated in Tables 2 and 3 for 2004 as an example. Added hay revenue was insufficient to offset lower cattle revenue given lesser beef production with greater breeding failure rates for spring calving when compared with fall calving. Hence, least fertilizer was the profit-maximizing, least LUI regret choice regardless of the inclusion of weather effects. 


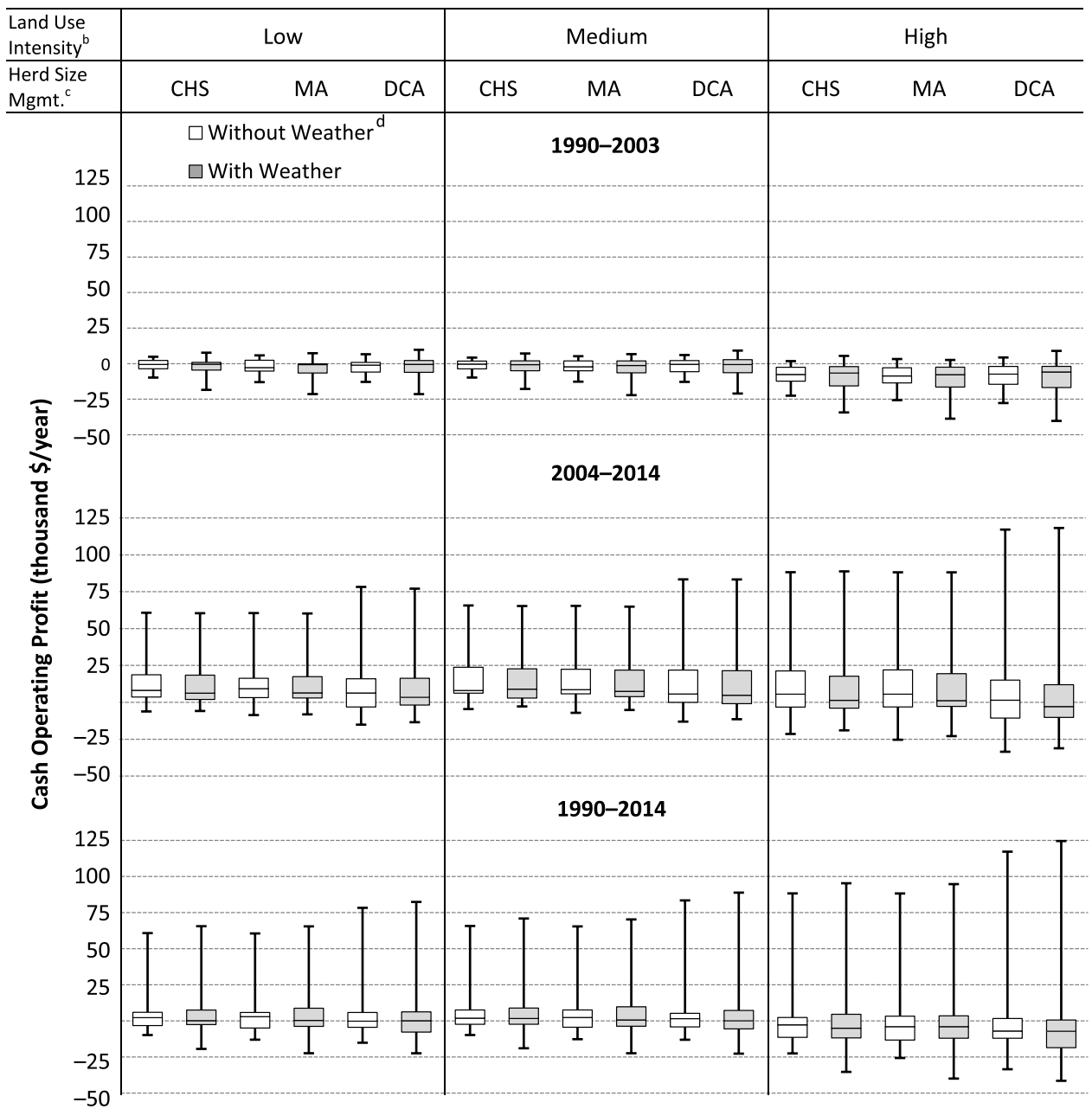

Figure 5. Minimum, median, maximum, and 25 and 75 percentiles of cash operating profit ${ }^{a}$ for spring calving herds by land use intensity, herd size management strategy, and cattle cycle or time period with weather effects excluded and included. ${ }^{a}$ Cash operating profits were period-specific and were calculated as the sale of cattle and excess hay less costs for feed and supplements, seed, fuel, fertilizer, twine, chemicals, veterinary services, operating interest, repairs, and medicine in $\$ / y e a r$. ${ }^{\mathrm{b}}$ Land use intensity is described in Table $1 .{ }^{\mathrm{c}}$ Herd size strategies were as follows: CHS = constant herd size cow herd size, $M A=$ cow herd size strategy using a ratio of two moving averages of feeder steer prices to signal an up- or downtrend in cattle prices, and DCA = dollar cost averaging strategy as described in quations (3)-(6). ${ }^{\mathrm{d}}$ See Figure 1 for production index adjustment because of weather conditions.

Over the second cycle, the CHS strategy was once again profit maximizing by having least HSM regret values for both low and medium LUI. With high fertilizer use, the MA strategy had $\$ 9.81$ more NPV than the CHS strategy. Further, in terms of LUI regret, highest profitability was achieved using the medium level of fertilizer use in the second cycle as was the case for fall calving. Hence, higher cattle prices in the second cycle did generate sufficient revenue to offset the marginal cost of added fertilizer, which also traded at higher prices (Figure 2). As with fall calving, the range of $\pi$ was smaller when weather risk was added in the second cycle. The $25^{\text {th }}$ and $75^{\text {th }}$ percentile range increased but to a lesser extent when compared with fall calving. However, weather effects led to a greater range of $\pi$ and in a more positively skewed fashion in comparison with fall calving (Figures 4 and 5). The second cycle proved more profitable than the first cycle given higher 
cattle and hay prices (Figure 2), which were sufficient to offset greater fertilizer, seed, and corn prices.

The 25-year analysis for spring calving led to the same profit-maximizing HSM strategy, CHS, again regardless of LUI or weather effects. Medium fertilizer use was profit maximizing with least LUI regret. High LUI was not justifiable and led to highest income risk (Figure 5).

In comparison with fall calving, the optimal HSM strategy was clearly the CHS strategy as that choice did not vary by cycle or with weather effects. Profit-maximizing fertilizer use was a less obvious choice as the first cycle with lower cattle and input prices offered less opportunity to recover added input cost.

\section{Conclusions}

This study examined the profitability of three HSM strategies under a variety of production conditions (fall vs. spring calving and LUI driven by fertilizer use) with and without simulated weather effects (Table 4). Under fall calving, the countercyclical HSM strategy based on anticipated price trend (MA) did show higher NPV of cash operating profit and minimum regret when compared with the DCA and CHS strategies for the majority of LUI $\times$ cattle cycle $\times$ weather effects combinations summarized in Table 5. Instituting an MA strategy, however, requires additional time devoted to management in comparison with the CHS strategy, and thus producers should weigh this trade-off when considering the use of an MA strategy. For fall calving, looking at the optimal fertilizer use for each cycle (low or medium for the first cycle pending inclusion of weather effects; medium or high for the second cycle, again pending inclusion of weather effects; and medium for the entire period), regret with the CHS strategy was less than $\$ 4,250$ for any of the periods whether weather effects were included or not. Satisficing $\$ 4,250$ at maximum and over 25 years may therefore well favor CHS in comparison with a more management-intensive MA strategy. For spring calving operations, this research showed the CHS HSM strategy to exhibit least regret regardless of LUI, weather effects, or cattle cycle. As with fall calving, the highest level of fertilizer use to increase stocking rate was least profitable and could be discouraged. For both fall and spring calving, regret observations suggested that medium LUI, to ensure greater hay sales in comparison with least fertilizer use, was both profit maximizing in general and led toward the lowest range in cash operating profit. Highest fertilizer use with greatest stocking rate was least profitable and most risky. Over the entire period, results suggested that producers would have maximized profit, without heightened exposure to income risk, if they had (1) chosen fall calving, (2) not increased stocking rate but added fertilizer to increase hay sales, and (3) chosen the MA HSM strategy. Noteworthy was that the CHS strategy was a close second choice. This advice held for that period but may well differ for the future.

In contrast to Lawrence (2002), a DCA strategy was not found to be superior to a CHS strategy when examined under a fixed land constraint and resulting on-farm forage limitations. Similar to previous findings (Bentley and Shumway, 1981; Hamilton and Kastens, 2000; Trapp, 1986), a countercyclical MA strategy was found to be more profitable on average than a CHS strategy under fall calving conditions with greater cattle output (fewer breeding failures than spring calving). Additionally, previous cow-calf herd management research had not examined an MA strategy as a method to increase profitability. This research thus contributes to literature on countercyclical HSM strategies by quantifying estimated impacts of capitalizing on cyclical market behavior using a popular investment technique.

Although this research examined various management decisions related to fertilizer application, stocking rates, and heifer retention, they were analyzed at relatively small scale and holding land resources constant. At larger scale, marginal gains using the MA strategy would be greater. Further, a 10- to 27-month MA price ratio was used to signal price trend changes. Different-length MA prices would lead to different timing of signals, and larger increments or decrements in herd 
size may have led to different outcomes. Finally, FORCAP modeling of weather risk was performed for northwest Arkansas conditions. These conditions are different for other regions of the country and will vary with time. Finally, results may have differed with year-round calving season management, and weather may also affect cattle performance (weight gain and reproductive performance). This aspect was not modeled.

Author ORCIDs. (D) Michael Popp 0000-0003-4505-2675

Financial support. This work was support by U.S. Department of Agriculture, National Institute of Food and Agriculture Hatch under project 02487.

\section{References}

Bentley, E., and C.R. Shumway. "Adaptive Planning over the Cattle Price Cycle." Southern Journal of Agricultural Economics 13, 1(1981):139-48.

Bierlen, R., P. Barry, B. Dixon, and B. Ahrendsen. "Credit Constraints, Farm Characteristics, and the Farm Economy: Differential Impacts on Feeder Cattle and Beef Cow Inventories." American Journal of Agricultural Economics. 80, 4(1998):708-23.

Caldwell, J., K. Coffey, J. Jennings, D. Philipp, A. Young, J. Tucker, D. Hubbell, et al. "Performance by Spring and Fall-Calving Cows Grazing with Full, Limited, or No Access to Toxic Neotyphodium coenophialum-Infected Tall Fescue. Journal of Animal Science 91, 1(2013):465-76.

Gadberry, S. Composition of Selected Livestock Feeds. Little Rock: University of Arkansas Cooperative Extension Service, FSA3043, 2015. Internet site: https://www.uaex.edu/publications/PDF/FSA-3043.pdf (Accessed August 23, 2017).

Griffith, A.P., K.H. Burdine, and D.P. Anderson. "Managing the Beef Cattle Herd through the Cattle Cycle." Surviving the Farm Economy Downturn. College Station: Agricultural and Food Policy Center, Texas A\&M University, 2017, pp. 54-58.

Hamilton, S., and T. Kastens. "Does Market Timing Contribute to the Cattle Cycle." American Journal of Agricultural Economics 82, 1(2000):82-96.

Hardie, I.W. "Comparative Rents for Farmland and Timberland in a Subregion of the South." Southern Journal of Agricultural Economics 16, 2(1984):1-9.

Hughes, H. "Major Issues in the US Livestock Industry under CUSTA." Paper presented at the Conference on Challenges in Agricultural Trade under CUSTA, Fargo, North Dakota, 2000.

Huneycutt, H.J., C.P. West, and J.M. Phillips. Responses of Bermudagrass, Tall Fescue, and Tall Fescue-Clover to Broiler Litter and Commercial Fertilizer. Arkansas Agricultural Experiment Station Bulletin 913. Fayetteville: Arkansas Agricultural Experiment Station, University of Arkansas, 1988.

Lawrence, J.D. Profiting from the Cattle Cycle: Alternative Cow Herd Investment Strategies. Ames: Iowa State University, Beef Reports, 2002. Internet site: http://lib.dr.iastate.edu/beefreports_2001/19 (Accessed August 24, 2017).

Lutes, J., and M. Popp. "Switchgrass as an Income Stabilizing Crop for Cow-calf Producers Impacted by Drought." Paper presented at the Agricultural and Applied Economics Association and Western Agricultural Economics Association Annual Meeting, San Francisco, California, July 26-28, 2015.

Mathews, K.H., Jr., W.F. Hahn, K.E. Nelson, L.A. Duewer, and R.A. Gustafson. U.S. Beef Industry: Cattle Cycles, Price Spreads, and Packer Concentration. Washington, DC: U.S. Department of Agriculture, Economic Research Service, Technical Bulletin No. 1874, 1999. Internet site: https://www.ers.usda.gov/publications/pub-details/?pubid=47247 (Accessed August 28, 2017).

Mississippi State University. Delta 2014 Planning Budgets. Mississippi State: Department of Agricultural Economics, Mississippi State University, 2014. Internet site: https://www.agecon.msstate.edu/whatwedo/budgets/docs/14/ MSUDELTA14.pdf (Accessed May 22, 2019).

Park, H., and R.T. Fortenberry. "The Effect of Ethanol Production on the U.S. National Corn Price." Staff Paper No. 523, Madison: University of Wisconsin-Madison, 2007.

Popp, M., S.A. Smith, D. Keeton, and W. Maples. "Forage \& Cattle Planner (FORCAP v 2)." Fayetteville: Department of Agricultural Economics and Agribusiness, University of Arkansas, 2014. Internet site: http://agribusiness.uark.edu/ decision-support-software.php (Accessed May 5, 2014).

Ritchie, H.D., and P.T. Anderson. "Calving Difficulty in Beef Cattle: Part 1." Beef Cattle Handbook. Ames: Iowa Beef Center, Iowa State University, 1994, pp. 1-4. Internet site: http://www.iowabeefcenter.org/bch/CalvingDifficultyl.pdf (Accessed May 3, 2019).

Rosen, S. "Dynamic Animal Economics." American Journal of Agricultural Economics 69, 3(1987):547-57.

Smith, S.A., M. Popp, D. Keeton, C. West, K. Coffey, L. Nalley, and K. Brye. 2016. "Economic and Greenhouse Gas Emission Response to Pasture Species Composition, Stocking Rate, and Weaning Age by Calving Season, Farm Size, and Pasture Fertility." Agricultural and Resource Economics Review 45, 1(2016):98-123. 
Smith, S.A., J.D. Caldwell, M. Popp, K.P. Coffey, J.A. Jennings, M.C. Savin, and C.F. Rosenkrans, Jr. "Tall Fescue Toxicosis Mitigation Strategies: Comparisons of Cow-Calf Returns in Spring- and Fall-Calving Herds." Journal of Agricultural and Applied Economics 44, 4(2012):577-92.

Tester, C. "Profitability Analysis of Varying Herd Sizes Based on Price Signals in Cow-Calf Operations." Bachelor's thesis, Department of Agricultural Economics and Agribusiness, University of Arkansas, Fayetteville, 2017.

Trapp, J.N. "Investment and Disinvestment Principles with Non-constant Prices and Varying Farm Size Applied to BeefBreeding Herds." American Journal of Agricultural Economics 68, 3(1986):691-703.

U.S. Department of Agriculture, National Agricultural Statistics Services (USDA-NASS). "Quick Stats” [Database]. Washington, DC: USDA-NASS, 2014. Internet site: https://quickstats.nass.usda.gov/ (Accessed June 15, 2017).

U.S. Department of Agriculture, National Agricultural Statistics Services (USDA-NASS). Overview of United States Cattle Industry. Washington, DC: USDA-NASS, 2016. Internet site: https://downloads.usda.library.cornell.edu/usda-esmis/files/ 8s45q879d/9z903258h/qz20sw09p/USCatSup-06-24-2016.pdf (Accessed May 22, 2019).

U.S. Department of Agriculture, National Agricultural Statistics Services (USDA-NASS). "CropScape- Cropland Data Layer" [Database]. Washington, DC: USDA-NASS, 2017. Internet site: https://nassgeodata.gmu.edu/CropScape/ (Accessed August 24, 2017).

U.S. Department of Agriculture, National Agricultural Statistics Services (USDA-NASS). Beef Cow Herd Size by Inventory and Sales. Washington, DC: USDA-NASS, 2019. Internet site: https://www.nass.usda.gov/Publications/AgCensus/2017/ Full_Report/Volume_1,_Chapter_1_US/st99_1_0015_0016.pdf (Accessed May 22, 2019).

Cite this article: Tester CA, Popp MP, Kemper NP, Nalley LL, and West G (2019). Impact of Weather and Herd Size Management on Beef Cow Profitability. Journal of Agricultural and Applied Economics 51, 545-567. https://doi.org/ $10.1017 /$ aae.2019.13 